\title{
Hemoglobin Variability Does Not Predict Mortality in Peritoneal Dialysis Patients
}

\author{
Ho-Ching Chen, MD; Kuan-Hsing Chen, MD; Yu-Jr Lin'1, MS; \\ Chee-Jen Chang², MD, PhD; Ya-Chung Tian, MD, PhD; Chih-Wei Yang, MD, PhD; \\ Cheng-Chieh Hung, MD, PhD
}

Background: Hemoglobin variability in hemodialysis patients treated with erythropoiesisstimulating agents has been used to evaluate mortality and comorbidity. Different outcomes have been reported in American and European hemodialysis patients. There are, however, few studies of the effects of hemoglobin variability in peritoneal dialysis patients.

Methods: We investigated hemoglobin variability in 363 peritoneal dialysis patients over 2 years to evaluate mortality and the association with comorbidity, peritonitis, and hospitalization. The hemoglobin of all patients selected for the study had been monitored for at least 6 months (April 2008 to September 2008). We assessed hemoglobin variability as fluctuations from the target hemoglobin level (11-12.5 g/dL). We defined the following 6 patient groups on the basis of hemoglobin patterns: consistently low $(<11 \mathrm{~g} / \mathrm{dL})$, consistently target range (11-12.5 g/dL), consistently high (> $12.5 \mathrm{~g} / \mathrm{dL})$, low-amplitude fluctuation with low hemoglobin levels, low-amplitude fluctuation with high hemoglobin levels, and high amplitude fluctuation.

Results: $\quad$ Only $2 \%$ of patients maintained a stable hemoglobin level within the target range and $46.8 \%$ of patients exhibited consistently low hemoglobin levels. After 2 years of observation, there was no difference in mortality as assessed by Kaplan-Meier analysis. There were also no differences in peritonitis and hospitalization between the 6 groups. However, the length of hospital stay was longer in the high amplitude fluctuation group $(p=0.008)$.

Conclusion: Hemoglobin variability does not predict mortality in peritoneal dialysis patients.

(Chang Gung Med J 2012;35:79-87)

Key words: anemia, erythropoiesis-stimulating agent, hemoglobin variability, mortality, peritoneal dialysis

A

nemia treatment has changed since the introduc-

use of erythropoiesis-stimulating agents (ESAs) and tion of epoetin alfa in $1989 .{ }^{(1)}$ The widespread intravenous iron have greatly improved anemia care

\footnotetext{
From the Department of Nephrology; 'Resource Center for Clinical Research, Chang Gung Memorial Hospital at Linkou, Chang Gung University College of Medicine, Taoyun, Taiwan; ${ }^{2}$ Graduate Institute of Clinical Medical Science, College of Medicine, Chang Gung University, Taoyuan, Taiwan.

Received: Mar. 29, 2011; Accepted: Sep. 15, 2011

Correspondence to: Dr. Cheng-Chieh Hung, Department of Nephrology, Chang Gung Memorial Hospital at Linkou. 5, Fusing St., Gueishan Township, Taoyuan County 333, Taiwan (R.O.C.) Tel: 886-3-3281200 ext. 8181; Fax: 886-3-3288662;

E-mail: cchung9651@yahoo.com
} 
in end-stage renal disease (ESRD) patients, with relief of anemia symptoms, improved quality of life, and decreased blood transfusion rates. ${ }^{(2,3)}$ Previous randomized clinical trials analyzed by an intentionto-treat approach have not shown benefits in maintaining physiologically normal hemoglobin levels in hemodialysis and chronic kidney disease patients and have reported an increase in cardiovascular events and complications associated with both higher and lower hemoglobin levels. ${ }^{(4-6)}$ The target of a "normal" hemoglobin range in ESRD and chronic kidney disease patients remains to be elucidated. The National Kidney Foundation Kidney Disease Outcomes Quality Initiative has developed clinical guidelines for targeting heemoglobin levels between 11-12 g/dL for patients with ESRD. ${ }^{(7)}$ Several studies showed that about $30-38 \%$ of patients maintain this range at any point of time. . $^{(7,8)}$

Fishbane and Berns describe the phenomenon of hemoglobin fluctuation and cycling passing through the target range in contrast to healthy individuals in whom hemoglobin levels are maintained in a narrow physiological range. In clinical practice, ${ }^{(9)}$ the ESA dosage is often adjusted according to the mean hemoglobin level and hemoglobin cycling and haemoglobin excursions (definition: half of hemoglobin cycling duration) are ignored. ${ }^{(9)}$ Different methods have been used to quantify the degree of hemoglobin variability but currently, none of the previously described methods reflect all aspects of variability. ${ }^{(10-13)}$ One promising method for assessing hemoglobin levels is the use of distinct categories of hemoglobin level changes compared with the target level over a 6-month period. ${ }^{(10)}$ This approach makes it easier to quantify hemoglobin variability trends in clinical practice.

Large population-based studies of hemoglobin variability performed in hemodialysis and chronic kidney disease patients have revealed an association with decreased survival, comorbidity, and hospitalizations. ${ }^{(10,11,14,15)}$ However, a recent study reported that hemoglobin variability did not independently predict mortality in European hemodialysis patients. ${ }^{(16)}$ There have been no related hemoglobin variability studies in peritoneal dialysis patients, who have less blood loss with less impact on hemoglobin levels than hemodialysis patients. The aims of our study were to analyze the effects of hemoglobin variability in peritoneal dialysis patients at a single medical center and to assess any difference between the hemodialysis and peritoneal dialysis populations.

\section{METHODS}

This clinical study followed the Declaration of Helsinki and was approved by the Medical Ethics Committee of Chang Gung Memorial Hospital. The institutional review board approval number is 982062B. The study subjects included patients undergoing outpatient peritoneal dialysis at Chang Gung Memorial Hospital Medical Center, Linkou. For the retrospective part of the study, we reviewed patient histories since January 1, $2008(n=405)$. We then observed patients who were maintained on peritoneal dialysis (excluding those who dropped out, transferred to other hospitals, or died) for a further 3 months. These patients $(n=390)$ were further followed for the duration of the inclusion period of 6 months (April 1, 2008 to September 30, 2008). Finally, data for all patients in the study at that point $(\mathrm{n}=363)$ were collected and analyzed, including basic patient characteristics, as well as comorbid disease, chronic kidney disease etiology, biochemistry data, residual renal function, total clearance function, ESA dosage, and medications administered, including iron, oral vitamin D, and phosphate binders (Fig. 1). Hemoglobin data were collected at least 3 times in the 6-month inclusion period. Patients who underwent frequent blood transfusions, recovered renal function, transferred care, changed dialytic modalities, received renal transplants, or died during the 6-

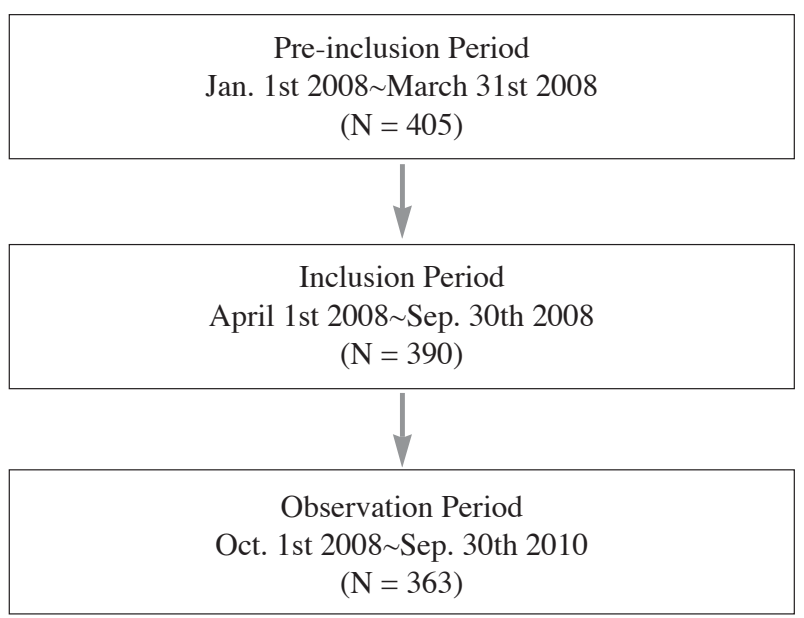

Fig. 1 Flowchart of inclusion of peritoneal dialysis patients. 
month inclusion period were excluded. Time to death from any cause was the primary outcome in the 2year observation period. Additionally, peritoneal dialysis-related peritonitis and hospitalization causes during the 2-year observation period were analyzed.

\section{Assessment of hemoglobin variability}

Hemoglobin levels were grouped according to categories described by Ebben and colleagues and were classified as low $(11.0 \mathrm{~g} / \mathrm{dL}),{ }^{(10)}$ within target (11.0 to $12.5 \mathrm{~g} / \mathrm{dL})$, or high $(12.5 \mathrm{~g} / \mathrm{dL})$ from April 1 , 2008 to September 30, 2008. To assess the frequency and size of the fluctuations in hemoglobin levels over time, we defined the following 6 groups of patients on the basis of their overall pattern of fluctuation: HA group (high-amplitude fluctuation; low, target-range, and high hemoglobin levels within the 6 month period), high group (consistently high levels for the entire 6 months), Target group (consistently within the target range for the entire 6 months), Low group (consistently low for the entire 6 months), LAH group (low-amplitude fluctuation with high hemoglobin levels; target-range or high hemoglobin levels within the 6-month period), and LAL group (low-amplitude fluctuation with low hemoglobin levels; low or target-range hemoglobin levels within the 6-month period) (Fig. 2).

\section{Adequacy of peritoneal dialysis}

Weekly total $\mathrm{Kt} / \mathrm{V}$ urea and weekly total creatinine clearance $(\mathrm{CCr})$ were calculated from dialysate and urine collected over a $24-\mathrm{h}$ period. The distribution volume of urea $(\mathrm{V})$ was calculated using the Watson equation. ${ }^{(17)}$ Weekly renal $\mathrm{Kt} / \mathrm{V}$ urea and weekly renal $\mathrm{CCr}$ were used to assess residual renal function.

\section{Statistical analysis}

Descriptive statistics are presented as mean \pm SD. All variables were tested for normal distribution using the Q-Q plot and Kolmogorov-Smirnov test. Means of continuous and categorical variables were compared across groups on the basis of hemoglobin variability using the Kruskal-Wallis test, chi-square
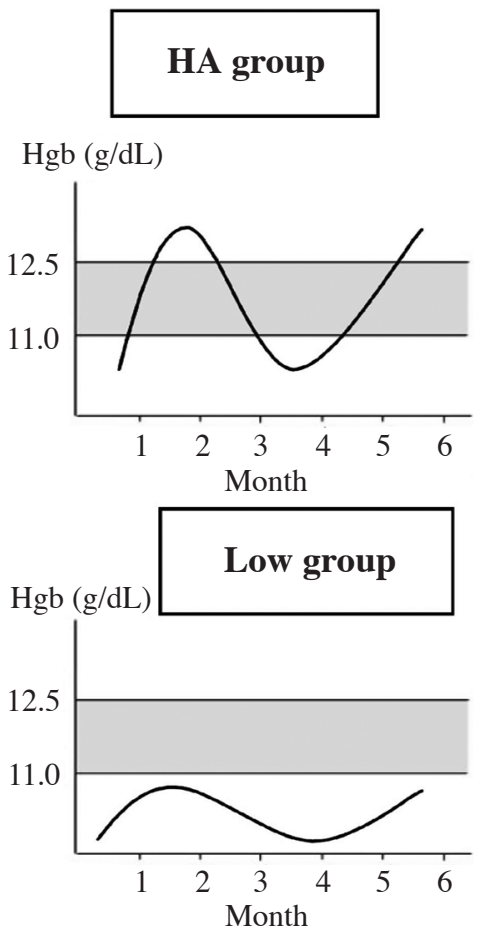
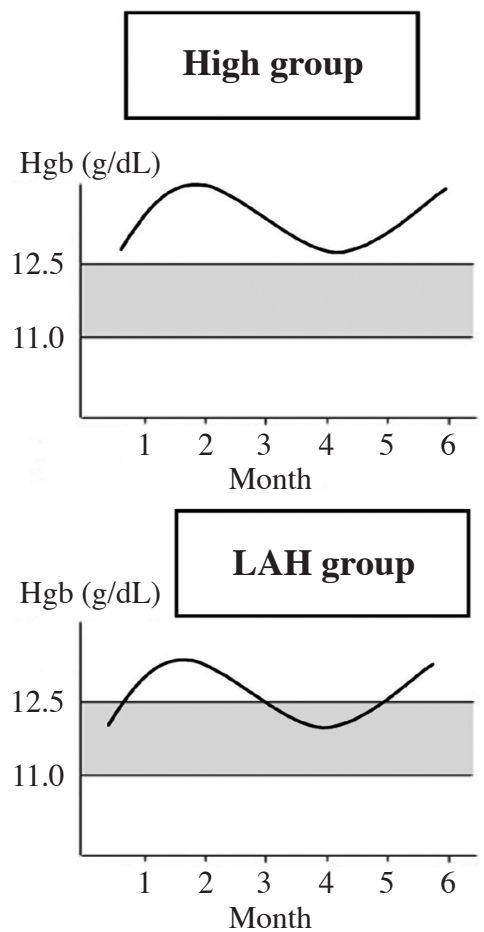

Target group
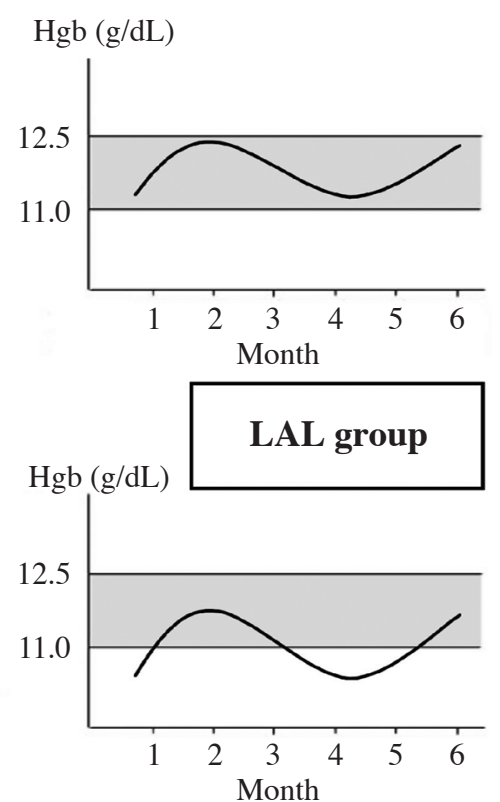

Fig. 2 The six hemoglobin variability groups. Abbreviations used: Hgb: hemoglobin; HA: high-amplitude fluctuation; High: consistently high; Target: consistently within the target range; Low: consistently low; LAH: low-amplitude fluctuation with high hemoglobin levels; LAL: low-amplitude fluctuation with low hemoglobin levels. 
test, and Fisher's exact test. The Bonferroni adjustment was used for multiple significant findings for results of multiple comparisons. Patient survival was estimated using Kaplan-Meier methods to evaluate survival to 24 months. Survival curves by hemoglobin categories were compared using the log-rank test. Peritonitis and hospitalization were assessed for relationship to hemoglobin variation pattern by the incidence rate.

All statistical analyses were performed using SPSS 18.0 and R 2.11.0.

\section{RESULTS}

\section{Patient characteristics}

Data were received from 363 peritoneal dialysis patients during the entire six months (April 2008 to September 2008) and at least 3 or more hemoglobin values were obtained; for most subjects, monthly lab data (six values) were obtained in our hospital. Patients were followed for a 2-year observation period. Table 1 describes the baseline characteristics, comorbid disease, and etiology of chronic kidney disease. Only $2 \%$ of patients maintained stable hemoglobin levels within the target range while
$46.8 \%$ of the patients exhibited consistently low hemoglobin levels during the observation period. There was a higher prevalence of glomerulonephritis $(46 \%)$ than diabetic mellitus nephropathy $(13.5 \%)$ in the peritoneal dialysis patient population.

Table 2 shows the patient biochemistry laboratory data and medication use. The ESA total dose per month was limited by medical policy; therefore there was no ESA use in the high group. Other medications were used according to current clinical practice guidelines.

\section{Primary outcome}

After the complete follow-up of 2 years, there were 23 deaths $(6.3 \%)$ in the total peritoneal dialysis population. Using Kaplan-Meier analysis and comparisons with the log rank test $(p=0.833)$, there were no significant differences associated with mortality between hemoglobin variability categories (Fig. 3). Cardiovascular disease (19\%) and infection $(23.8 \%)$ were the main causes of mortality.

Peritonitis and hospitalization results are shown in Table 3. There were no significant differences in peritonitis incidence, hospitalization, or rates of admission for infection between hemoglobin vari-

Table 1. Patient Characteristics by Hemoglobin Variability

\begin{tabular}{|c|c|c|c|c|c|c|}
\hline Patient Characteristics & $\mathrm{HA}(\mathrm{n}=22)$ & $\operatorname{High}(n=4)$ & Target $(n=9)$ & Low $(n=170)$ & LAH $(n=16)$ & $\operatorname{LAL}(n=142)$ \\
\hline$\%$ of total $(\mathrm{n}=363)$ & 6.1 & 1.1 & 2.5 & 46.8 & 4.4 & 39.1 \\
\hline Age (years) & $48.7 \pm 15.5$ & $48.0 \pm 9.4$ & $55.6 \pm 5.6$ & $51.2 \pm 13.2$ & $49.4 \pm 14.4$ & $51.7 \pm 14.8$ \\
\hline Gender male & $9(40.9 \%)$ & $4(100 \%)$ & $5(55.6 \%)$ & $46(27.1 \%)$ & $10(62.5 \%)$ & $47(33.1 \%)$ \\
\hline History of DM & $2(9.1 \%)$ & $1(25 \%)$ & $1(11.1 \%)$ & $33(19.4 \%)$ & $2(12.5 \%)$ & $27(19.0 \%)$ \\
\hline History of CVD & $3(13.6 \%)$ & 0 & $1(11.1 \%)$ & $35(20.6 \%)$ & $3(18.8 \%)$ & $20(14.1 \%)$ \\
\hline History of hypertension & $19(86.4 \%)$ & $2(50 \%)$ & $7(77.8 \%)$ & $132(77.6 \%)$ & $14(87.5 \%)$ & $111(78.2 \%)$ \\
\hline History of CVA & $1(4.5 \%)$ & 0 & 0 & $6(3.5 \%)$ & 0 & $7(4.9 \%)$ \\
\hline History of Cancer & 0 & 0 & $1(11.1 \%)$ & $9(5.3 \%)$ & 0 & $9(6.3 \%)$ \\
\hline \multicolumn{7}{|l|}{ CKD etiology } \\
\hline $\mathrm{DM}$ & $2(9.1 \%)$ & $1(25 \%)$ & $1(11.1 \%)$ & $24(14.1 \%)$ & $1(6.3 \%)$ & $20(14.1 \%)$ \\
\hline GN & $16(72.7 \%)$ & $1(25 \%)$ & $5(55.6 \%)$ & $68(40.0 \%)$ & $7(43.8 \%)$ & $70(49.3 \%)$ \\
\hline Hypertension & $1(4.5 \%)$ & 0 & $1(11.1 \%)$ & $15(8.8 \%)$ & $1(6.3 \%)$ & $13(9.2 \%)$ \\
\hline Others & $3(13.6 \%)$ & $2(50 \%)$ & $2(22.2 \%)$ & $63(37.1 \%)$ & $7(43.8 \%)$ & $39(27.5 \%)$ \\
\hline
\end{tabular}

Abbreviations: HA: high amplitude fluctuation; LAH: low amplitude fluctuation with high hemoglobin; LAL: low amplitude with low hemoglobin; DM: diabetes mellitus; CVD: cardiovascular disease; CVA: cerebral-vascular disease; CKD: chronic kidney disease; GN: glomerulonephritis; NS: not significant. 
Table 2. Biochemistry and Medication by Hemoglobin Variability

\begin{tabular}{|c|c|c|c|c|c|c|}
\hline Patient characteristics & HA $(n=22)$ & $\operatorname{High}(n=4)$ & Target $(\mathrm{n}=9)$ & Low $(\mathrm{n}=170)$ & LAH $(n=16)$ & $\operatorname{LAL}(\mathrm{n}=142)$ \\
\hline \multicolumn{7}{|l|}{ Laboratory parameters } \\
\hline Leukocytes (x 103/ul) & $8.3 \pm 3.9$ & $7.4 \pm 0.5$ & $6.6 \pm 1.3$ & $7.7 \pm 2.3$ & $8.7 \pm 2.2$ & $8.1 \pm 2.6$ \\
\hline Hemoglobin (g/dL) & $11.2 \pm 0.6$ & $15.0 \pm 1.4$ & $11.6 \pm 0.2$ & $9.0 \pm 1.0$ & $12.6 \pm 0.6$ & $10.6 \pm 0.6$ \\
\hline Albumin $(\mathrm{g} / \mathrm{dL})$ & $3.8 \pm 0.4$ & $3.9 \pm 0.2$ & $3.7 \pm 0.5$ & $3.7 \pm 0.4$ & $3.9 \pm 0.4$ & $3.8 \pm 0.4$ \\
\hline Total cholesterol (mg/dL) & $189.9 \pm 21.1$ & $193.3 \pm 51.1$ & $206.2 \pm 43.3$ & $195.8 \pm 39.4$ & $187.7 \pm 34.9$ & $198.0 \pm 33.7$ \\
\hline Sodium (mg/dL) & $136.9 \pm 4.1$ & $139.1 \pm 3.6$ & $141.5 \pm 1.8$ & $137.2 \pm 3.5$ & $137.2 \pm 2.5$ & $137.5 \pm 3.7$ \\
\hline Potassium (mg/dL) & $3.7 \pm 0.7$ & $3.6 \pm 0.2$ & $3.8 \pm 0.3$ & $4.0 \pm 0.7$ & $3.9 \pm 0.4$ & $4.0 \pm 0.8$ \\
\hline Calcium (mg/dL) & $9.9 \pm 0.9$ & $10.0 \pm 1.0$ & $9.3 \pm 0.3$ & $9.9 \pm 0.7$ & $10.0 \pm 0.8$ & $9.8 \pm 0.8$ \\
\hline Phosphate (mg/dL) & $4.7 \pm 0.9$ & $4.6 \pm 1.0$ & $4.5 \pm 0.8$ & $5.3 \pm 1.0$ & $5.0 \pm 1.3$ & $5.0 \pm 1.0$ \\
\hline Transferrin saturation $\%$ & $32.1 \pm 15.2$ & $33.2 \pm 27.3$ & $30.9 \pm 9.0$ & $25.4 \pm 11.7$ & $22.8 \pm 5.9$ & $25.8 \pm 10.8$ \\
\hline Ferritin $(\mu \mathrm{g} / \mathrm{L})$ & $340.4 \pm 442.5$ & $55.8 \pm 60.9$ & $100.9 \pm 56.9$ & $344.9 \pm 475.0$ & $85.8 \pm 75.2$ & $265.3 \pm 347.0$ \\
\hline Intact parathyroid hormone $(\mathrm{pg} / \mathrm{mL})$ & $287.1 \pm 290.5$ & $119.4 \pm 88.5$ & $185.5 \pm 185.9$ & $375.0 \pm 423.5$ & $417.7 \pm 350.9$ & $313.7 \pm 378.9$ \\
\hline Renal Kt/V & $0.32 \pm 0.48$ & $0.45 \pm 0.77$ & $0.73 \pm 0.68$ & $0.15 \pm 0.24$ & $0.07 \pm 0.13$ & $0.23 \pm 0.34$ \\
\hline Total Kt/V & $2.4 \pm 0.4$ & $2.4 \pm 0.5$ & $2.5 \pm 0.5$ & $2.2 \pm 0.4$ & $2.0 \pm 0.2$ & $2.2 \pm 0.4$ \\
\hline Renal CCr (1/week/1.73 m²) & $17.3 \pm 40.1$ & $27.1 \pm 44.1$ & $36.4 \pm 38.2$ & $5.9 \pm 10.9$ & $5.7 \pm 11.2$ & $10.9 \pm 15.4$ \\
\hline Standard total CCr $\left(1 /\right.$ week $\left./ 1.73 \mathrm{~m}^{2}\right)$ & $69.4 \pm 30.1$ & $80.3 \pm 33.3$ & $86.4 \pm 33.0$ & $60.4 \pm 12.1$ & $57.2 \pm 13.2$ & $62.3 \pm 14.5$ \\
\hline \multicolumn{7}{|l|}{ Medications } \\
\hline ESA total dose per month & $12909 \pm 4929$ & 0 & $12630 \pm 5275$ & $19031 \pm 2759$ & $6125 \pm 4925$ & $16644 \pm 4426$ \\
\hline Iron agent (yes) & $8(36.4 \%)$ & $1(25 \%)$ & $1(11.1 \%)$ & $83(48.8 \%)$ & $5(31.3 \%)$ & $67(47.2 \%)$ \\
\hline ACE inhibitor or ARB use (yes) & $10(45.5 \%)$ & $1(25 \%)$ & $4(44.4 \%)$ & $84(49.4 \%)$ & $3(18.8 \%)$ & $68(47.9 \%)$ \\
\hline Oral Vitamin D (yes) & $7(31.8 \%)$ & $2(50 \%)$ & $3(33.3 \%)$ & $62(36.7 \%)$ & $6(37.5 \%)$ & $46(32.4 \%)$ \\
\hline Phosphate binder (yes) & $21(95.5 \%)$ & $3(75 \%)$ & $6(66.7 \%)$ & $158(92.9 \%)$ & $16(100 \%)$ & $132(93.0 \%)$ \\
\hline
\end{tabular}

Abbreviations: HA: high amplitude fluctuation; LAH: low amplitude fluctuation with high hemoglobin; LAL: low amplitude with low hemoglobin; ESA: erythropoiesis-stimulating agents; ACE: angiotensin-converting enzyme; ARB: angiotension receptor blocker; Ccr: creatinine clearance; NS: not significant.

ability groups. However, a longer hospital stay was noted in the HA hemoglobin group (mean: 12.8 days; $p=0.008$ ). Multiple comparisons by the Bonferroni test revealed significant differences for the HA group compared with low, LAH and LAL groups.

\section{DISCUSSION}

Our results showed no differences among the 6 groups of patients in comorbid disease, chronic kidney disease etiology, albumin, total cholesterol, potassium, calcium, intact parathyroid hormone, transferrin saturation, and oral medications (iron agents, ACEi/ARB, vitamin D, phosphate binders). ESA use in each group reflected the differences in the mean hemoglobin values. After 2 years observa- tion, we conclude that hemoglobin variability cannot independently predict mortality in peritoneal dialysis patients. In related complications, including peritonitis, hospitalization, and the rate of hospitalization due to infection, the differences between the hemoglobin variability groups also did not reach statistical significance. However, the increase in the average hospital stay for the HA group was statistically significant.

Clinically, anemia in chronic kidney disease is affected by many factors, including factors related to patient characteristics, iron deficiency, infection, inflammation, malignancy, and, most importantly, guidelines on ESA dosage and frequency of administration. Recently, one study suggested that discontinuation rather than reduction of ESA treatment was more appropriate for hemodialysis patients when 
hemoglobin levels $>13 \mathrm{~g} / \mathrm{dL}$ were observed. ${ }^{(18)}$ Therefore, we often adjust the ESA dosage according to the mean hemoglobin level and ignore real hemoglobin cycling and hemoglobin excursions. ${ }^{(9)}$ Hemoglobin overshooting may be associated with various complications, including hypertension, ${ }^{(19)}$ high platelet counts, ${ }^{(20)}$ and thrombotic events. ${ }^{(21)}$ Our study showed a significantly reduced ESA dosage in

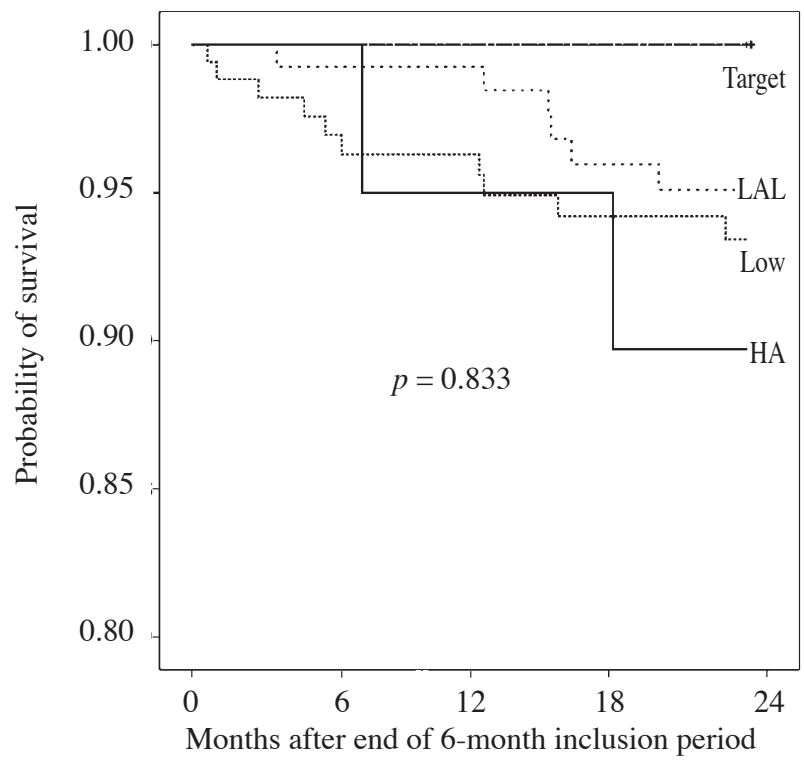

Fig. 3 Kaplan-Meier analysis showing no significant difference associated with mortality in each hemoglobin variability category $(p=0.833)$. There was no patient mortality in the high group and LAH group, so these two groups are not shown in the figure. Abbreviations used: HA: high-amplitude fluctuation; High: consistently high; Target: consistently within the target range; Low: consistently low; LAH: low-amplitude fluctuation with high hemoglobin levels; LAL: lowamplitude fluctuation with low hemoglobin levels. patients who maintained low amplitude in conjunction with high hemoglobin levels (LAH group), while patients exhibiting high amplitude in conjunction with average hemoglobin levels within the target range (HA group) had ESA usage similar to that of other groups. In addition, lower ferritin was also noted in the higher mean hmoglobin levels in the high, target and LAH groups, which is compatible with clinical observation with ferritin utilization. On the other hand, patients in the target group had better residual renal function compared with those in the other groups, possibly because they had more preserved renal function which influenced the hemoglobin fluctuation.

Hemoglobin levels change over time, and one study showed that only about $5 \%$ of ESRD patients maintained target levels after a few months of observation. ${ }^{(8)}$ Another study reported that over $90 \%$ of patients experienced hemoglobin cycling. ${ }^{(10)}$ The mean number of hemoglobin excursions was $3.1 \pm$ 1.1 per patient/year. The mean amplitude per hemoglobin excursion was $2.51 \pm 0.89 \mathrm{~g} / \mathrm{dL}$ and the mean duration of hemoglobin excursions was 10.3 \pm 5.1 weeks. ${ }^{(9)}$ These fluctuations inhemoglobin levels in ESRD patients are distinct from normal physiological changes, leading to speculation that substantial short-term changes in hemoglobin levels and administration of high dosage ESA are two factors likely to affect prognosis. As described above, the large amplitude and periodicity changes in hemoglobin levels in patients differed significantly from levels within the narrow $\mathrm{K} / \mathrm{DOQI}$ hemoglobin range. In a previous study in hemodialysis and chronic kidney disease patients using multiple calculation methods, hemoglobin variability was demonstrated to significantly affect the prognosis. Survival analyses indicat-

Table 3. Peritonitis and Hospitalization by Hemoglobin Variability

\begin{tabular}{|c|c|c|c|c|c|c|c|}
\hline Complication & $\mathrm{HA}(\mathrm{n}=22)$ & $\operatorname{High}(n=4)$ & Target $(n=9)$ & Low $(n=170)$ & $\mathrm{LAH}(\mathrm{n}=16)$ & $\operatorname{LAL}(\mathrm{n}=142)$ & $p$-value \\
\hline Peritonitis $(\%)$ & $5(22.7 \%)$ & 0 & $2(22.2 \%)$ & $41(24.1 \%)$ & $4(25 \%)$ & $41(28.9)$ & NS \\
\hline Hospitalization (\%) & $12(54.5 \%)$ & $1(25 \%)$ & $4(44.4 \%)$ & $88(51.8 \%)$ & $6(37.5 \%)$ & $64(45.1 \%)$ & NS \\
\hline Admission for infection (\%) & $57.7 \%$ & 0 & $75 \%$ & $50.6 \%$ & $44.4 \%$ & $52 \%$ & NS \\
\hline Average LOS (days) & $12.8 \pm 16.1^{\mathrm{a}}$ & $1.0 \pm 2.0$ & $2.5 \pm 3.6$ & $5.7 \pm 7.7 \mathrm{~b}$ & $2.9 \pm 4.0^{\mathrm{b}}$ & $5.7 \pm 7.4^{b}$ & 0.008 \\
\hline
\end{tabular}

Means within each column (a compared with b) are significantly different at $p<0.05$ by Bonferroni test.

Abbreviations: HA: high amplitude fluctuation; LAH: low amplitude fluctuation with high hemoglobin; LAL: low amplitude with low hemoglobin; LOS: length of hospital stay; NS: not significant. 
ed that each $1 \mathrm{~g} / \mathrm{dL}$ increase in the residual standard deviation was associated with a $33 \%$ increase in the rate of death. ${ }^{(11)}$ In another study, hemoglobin variability was also shown to correlate with comorbidity and the rate of complications. ${ }^{(10)}$ In patients with chronic kidney disease, the same phenomenon was observed. ${ }^{(15)}$ While disrupted hemoglobin levels are an important symptom in patients with chronic kidney disease and ESRD, a recent large-scale study in Europe showed that hemoglobin variability does not independently predict mortality in hemodialysis patients. ${ }^{(16)}$

The association between hemoglobin variability and comorbidity/mortality in peritoneal dialysis patients has not been addressed before. In this study, we found that hemoglobin variability is not an independent predictor of clinical outcome in peritoneal dialysis patients. One possible reason for this finding is the inclusion of a high proportion of patients with glomerulonephritis in this study. Patients with glomerulonephritis have shown better outcomes than those with diabetic nephropathy in previous studies, which could have affected our results. On the other hand, because most peritoneal dialysis patients maintain residual renal function, they have a better prognosis than hemodialysis patients. In our study, only $2 \%$ of the patients maintained a target level of hemoglobin, partly because of the impact of health care policy that limits ESA use. In studies from other countries, higher doses of ESA were used, which may have been more effective in maintaining target levels of hemoglobin in 5-18\% of those patients, and may have affected their outcomes. ${ }^{(10)}$ Most mortality cases in our study occurred in the low and LAL groups, suggesting that lower hemoglobin levels correlate with higher mortality. This is consistent with previously reported findings. It should be noted that the small number of deaths in our study compared with a previous peritoneal dialysis survival analysis in Taiwan (2-year survival rate: $77.6 \%$ ) may have affected our results. ${ }^{(22)}$ The deaths observed were mainly due to infections and cardiovascular disease, which accounted for $23.8 \%$ and $19 \%$ of deaths, respectively.

Peritoneal dialysis patients have more peritonitis complications than hemodialysis patients. There was no difference in the peritonitis incidence rate between the groups in our study $(95 \% \mathrm{CI})$. Thus, the incidence of peritonitis was not affected by hemoglo- bin variability. Similarly, the overall hospitalization rate and the rate of hospitalization due to infection did not show differences between the groups with different hemoglobin levels. Our finding that patients in the HA group had a longer hospital stay could be explained by a higher rate of chronic inflammation or a poorer medical response in patients with greater fluctuation of hemoglobin.

There were several limitations in this study. First, the number of subjects was relatively small compared with previous hemodialysis studies. Second, because of the impact of medical policy, ESA use was limited, although few patients exhibited high hemoglobin levels; it is also possible that the high ESA dosage reported in previous studies may have affected patient outcomes, or that Asians have a different ideal range of hemoglobin compared with patients from other geographic areas. Third, our study of peritoneal dialysis patients included a larger population of patients with glomerulonephritis than with diabetes mellitus nephropathy, possibly beause of patient selection or convenience of medical care in Taiwan. Fourth, a 2-year follow-up period may not be long enough. Fifth, because this is a retrospective study, more research is needed to further analyze different formulations of ESA. Also, differences in heterogeneous distribution between our patient groups may have been related to ESA policy or other factors. Ebben et al's study also noted heterogeneous distribution even in a large study population (low: 1.8\%, target: $6.5 \%$, high: $2.0 \%$, LAL: $21.3 \%$, LAH: $28.9 \%$ and HA: $39.5 \% \mathrm{n}=152,846) .{ }^{(10)}$ Sixth, owing to multiple factors influencing mortality in our study, the hmoglobin fluctuation in the inclusion period may not have been a good predictor of mortality in peritoneal dialysis patients. Of course, our study has limitations in that data were collected retrospectively in one medical center and the obtained database therefore reflected only a small sample of the entire Taiwan dialysis population. We will further use the basis of our study to collect more patients to overcome the heterogeneous distribution of patient groups.

In conclusion, our preliminary study demonstrates that hemoglobin variability does not independently predict mortality in peritoneal dialysis patients. There also were no significant differences in peritonitis and hospitalization rates. However, the hospital stay was longer in the HA group. 


\section{Acknowledgement}

We appreciate the help provided by the peritoneal dialysis staff of Chang Gung Memorial Hospital, Linkou.

\section{REFERENCES}

1. Eschbach JW, Abdulhadi MH, Browne JK, Delano BG, Downing MR, Egrie JC, Evans RW, Friedman EA, Graber SE, Haley NR. Recombinant human erythropoietin in anemic patients with end-stage renal disease. Ann Intern Med 1989;111:992-1000.

2. Moreno F, Sanz-Guajardo D, Lopez-Gomez JM, Jofre R, Valderrabano F. Increasing the hematocrit has a beneficial effect on quality of life and is safe in selected hemodialysis patients. J Am Soc Nephrol 2000;11:335-42.

3. Lefebvre P, Vekeman F, Sarokhan B, Enny C, Provenzano R, Cremieux PY. Relationship between hemoglobin level and quality of life in anemic patients with chronic kidney disease receiving epoetin alfa. Curr Med Res Opin 2006;22:1929-37.

4. Besarab A, Bolton WK, Browne JK, Egrie JC, Nissenson AR, Okamoto DM, Schwab SJ, Goodkin DA. The effects of normal as compared with low hematocrit values in patients with cardiac disease who are receiving hemodialysis and epoetin. N Engl J Med 1998;339:584-90.

5. Singh AK, Szczech L, Tang KL, Barnhart H, Sapp S, Wolfson M, Reddan D; CHOIR Investigators. CHOIR Investigators: Correction of anemia with epoetin alfa in chronic kidney disease. N Engl J Med 2006;355:2085-98.

6. Pfeffer MA, Burdmann EA, Chen CY, Cooper ME, de Zeeuw D, Eckardt KU, Feyzi JM, Ivanovich P, Kewalramani R, Levey AS, Lewis EF, McGill JB, McMurray JJ, Parfrey P, Parving HH, Remuzzi G, Singh AK, Solomon SD, Toto R; TREAT Investigators. TREAT Investigators: A trial of darbepoetin alfa in type 2 diabetes and chronic kidney disease. N Engl J Med 2009;361: 2019-32.

7. KDOQI: Clinical practice guideline and clinical practice recommendations for anemia in chronic kidney disease-2007 update of hemoglobin target. Am J Kidney Dis 2007;50:471-530.

8. Lacson E Jr, Ofsthun N, Lazarus JM. Effect of variability in anemia management on hemoglobin outcomes in ESRD. Am J Kidney Dis 2003;41:111-24.

9. Fishbane S, Berns JS. Hemoglobin cycling in hemodialysis patients treated with recombinant human erythropoietin. Kidney Int 2005;68:1337-43.

10. Ebben JP, Gilbertson DT, Foley RN, Collins AJ. Hemoglobin level variability: Associations with comorbidity, intercurrent events, and hospitalizations. Clin J Am Soc Nephrol 2006;1:1205-10.

11. Yang W, Israni RK, Brunelli SM, Joffe MM, Fishbane S, Feldman HI. Hemoglobin variability and mortality in
ESRD. J Am Soc Nephrol 2007;18:3164-70.

12. West RM, Harris K, Gilthorpe MS, Tolman C, Will EJ. Functional data analysis applied to a randomized controlled clinical trial in hemodialysis patients describes the variability of patient responses in the control of renal anemia. J Am Soc Nephrol 2007;18:2371-6.

13. Agarwal AK, Silver MR, Reed JE, Dhingra RK, Liu W, Varma N, Stehman-Breen C. An open-label study of darbepoetin alfa administered once monthly for the maintenance of haemoglobin concentrations in patients with chronic kidney disease not receiving dialysis. J Intern Med 2006;260:577-85.

14. Brunelli SM, Lynch KE, Ankers ED, Joffe MM, Yang W, Thadhani RI, Feldman HI. Association of hemoglobin variability and mortality among contemporary incident hemodialysis patients. Clin J Am Soc Nephrol 2008;3: 1733-40.

15. Boudville NC, Djurdjev O, Macdougall IC, de Francisco AL, Deray G, Besarab A, Stevens PE, Walker RG, Ureña P, Iñigo P, Minutolo R, Haviv YS, Yeates K, Agüera ML, MacRae JM, Levin A. Hemoglobin variability in nondialysis chronic kidney disease: examining the association with mortality. Clin J Am Soc Nephrol 2009;4:1176-82.

16. Eckardt KU, Kim J, Kronenberg F, Aljama P, Anker SD, Canaud B, Molemans B, Stenvinkel P, Schernthaner G, Ireland E, Fouqueray B, Macdougall IC. Hemoglobin variability does not predict mortality in European hemodialysis patients. J Am Soc Nephrol 2010;21:176575.

17. Watson PE, Watson ID, Batt RD. Total body water volumes for adult males and females estimated from simple anthropometric measurements. Am J Clin Nutr 1980;33: 27-39.

18. Weiner DE, Miskulin DC, Seefeld K, Ladik V, Zager PG, Singh AK, Johnson HK, Meyer KB. Reducing versus discontinuing erythropoietin at high hemoglobin levels. J Am Soc Nephrol 2007;18:3184-91.

19. Chen J, Gul A, Sarnak MJ. Management of intradialytic hypertension: The ongoing challenge. Semin Dial 2006;19:141-5.

20. Beguin Y, Loo M, R'Zik S, Sautois B, Lejeune F, Rorive G, Fillet G. Effect of recombinant human erythropoietin on platelets in patients with anemia of renal failure: Correlation of platelet count with erythropoietic activity and iron parameters. Nippon Jinzo Gakkai Shi 1994;36: 1288-95.

21. Kooistra MP, van Es A, Marx JJ, Hertsig ML, Struyvenberg A. Low-dose aspirin does not prevent thrombovascular accidents in low-risk haemodialysis patients during treatment with recombinant human erythropoietin. Nephrol Dial Transplant 1994;9:1115-20.

22. Huang CC, Cheng KF, Wu HD. Survival analysis: comparing peritoneal dialysis and hemodialysis in Taiwan. Perit Dial Int 2008;Suppl 3:S15-20. 


\section{血紶素變化無法預測腹膜透析病人的死亡率}

\section{陳河卿 陳冠興 林育志 ${ }^{1}$ 張啓仁 ${ }^{2}$ 田亞中 楊智偉 洪振傑}

背 景：血色素變化使用在血液透析患者評估死亡率及合併症, 在美國和歐洲的研究在血液 透析患者有不同的結論。但是很少有研究來評估腹膜透析患者血色素的變化。本研 究是針對單一醫學中心腹膜透析患者血色素變化對死亡率的影響。

方 法: 這是一個回朔性研究 363 個腹膜透析的病例, 總共兩年的時間, 進一步分析血色素 和死亡率, 合併症, 腹膜炎和住院率的關係。根據腹膜透析患者血色素在目標血色 素 (11-12.5 g/dL) 的變化分爲六組。分別爲持續性偏低 $(<11 \mathrm{~g} / \mathrm{dL})$, 持續性在目標值 (11-12.5 g/dL), 持續性偏高 (>12.5 g/dL), 低波動合併低血色素, 低波動合併高血色 素, 高波動血色素。

結 果：只有 $2 \%$ 的患者可以維持在持續性在目標值的範圍, 有 $46.8 \%$ 的患者在持續性偏低的 血色素。經過雨年的時間, 在各組之間的死亡率並沒有顯著的差異。而在產生腹膜 炎的機率和住院率也沒有達到統計學上的差異。但是在高波動血色素的那一組有較 長的住院天數, 並達到統計學上的意義 $(p=0.008)$ 。

結 論 : 血色素變化並無法預測腹膜透析患者的死亡率。

(長庚醫誌 2012;35:79-87)

關鍵詞：貧血, 紅血球生成素, 血色素變化, 死亡率, 腹膜透析

長庚醫療財團法人林口長庚紀念醫院 腎臟科系; 臨床研究統計中心 ; 長庚大學 醫學院 2臨床醫學研究所 受文日期：民國100年3月29日；接受刊載：民國100年9月15日

通訊作者: 洪振傑醫師, 長庚醫療財團法人林口長庚紀念醫院 腎臟科系。桃園縣333龜山郷復興街5號。

Tel: (03)3281200轉8181; Fax: (03)3288662; E-mail: cchung9651@yahoo.com 